\title{
Desenvolvimento de reatores fotoeletroquímicos em fluxo utilizando material nanoestruturado sobre Ti, para degradação de um fármaco.
}

\section{Vitor Toshi Nishi (IC); Peterson Bueno de Moraes (PQ)}

\section{Resumo}

A presença de fármacos em águas superficiais, esgotos domésticos e industriais, é devido ao crescimento de produção e consumo, sendo que esses compostos não são totalmente eliminados pelos processos convencionais de tratamento, provocando efeitos deletérios no meio hídrico e na saúde pública. Na busca por tratamentos alternativos, o processo de fotoeletrocatálise mostra-se promissor. Este trabalho avaliou a confecção de eletrodos nanoestruturados de $\mathrm{TiO}_{2}$ e sua utilização para degradação do Citrato de Sildenafil, $\left(\right.$ Viagra $\left.^{\Theta}\right)$, via reator fotoeletroquímico operando em batelada.

Palavras Chave: Fotoeletrocatálise, Citrato de Sildenafil, Eletrodos de nano $\mathrm{TiO}_{2}$

\section{Introdução}

Uma consequência da expansão industrial e o crescimento demográfico nas cidades desenvolvidas ou em desenvolvimento é a presença de fármacos em águas superficiais devido ao lançamento de esgotos domésticos e industriais (MELO et al., 2009).

Esses medicamentos são recalcitrantes e, portanto, não são totalmente removidos pelos processos convencionais, provocando efeitos deletérios sobre os organismos aquáticos e no homem (FRANÇA, 2011).

Perante a isso, há recentemente a busca por novas tecnologias aplicáveis ao tratamento desses compostos. $O$ processo de fotoeletrocatálise utilizando nanoestruturas de $\mathrm{TiO}_{2}$ tem ganhado destaque (CAVALEIRO e HOSSON, 2006).

Esse trabalho tem como objetivo preparar eletrodos nanoestruturados de $\mathrm{TiO}_{2}$ visando aplicação para tratamento de soluções aquosas contendo Citrato de Sidenafil (C.S.).

\section{Resultados e Discussão}

Para desenvolvimento do eletrodo de $\mathrm{TiO}_{2}$, cortou-se uma placa de $\mathrm{Ti}$ de $4 \times 4 \mathrm{~cm}$. Em seguida, houve a ativação através de submersão por 2,5 minutos em solução decapante ( $\mathrm{HF}: 3 \mathrm{HNO}_{3}: 6 \mathrm{H}_{2} \mathrm{O}$ ) e seguido por 10 minutos em ultrassom. $\mathrm{Na}$ etapa seguinte, ocorreu a anodização da placa utilizando um contraeletrodo de $\mathrm{Ni}$, distante $5 \mathrm{~mm}$ e $700 \mathrm{rpm}$. Ambos os eletrodos estavam submersos em solução eletrolítica $(0,3 \% \quad H F)$ e submetidos a um potencial constante de $20 \mathrm{~V}$ por 120 minutos (anodização eletroquímica).

Finalmente, o eletrodo foi aquecido em mufla sob atmosfera de ar até $450^{\circ} \mathrm{C}$ (cristalização) para obtenção da fase Anatase e foi realizado uma microscopia eletrônica de varredura para a caracterização dos nanotubos.
Figura 1. Resultados obtidos na degradação fotoeletrocatalítica do C.S. Fonte: O autor

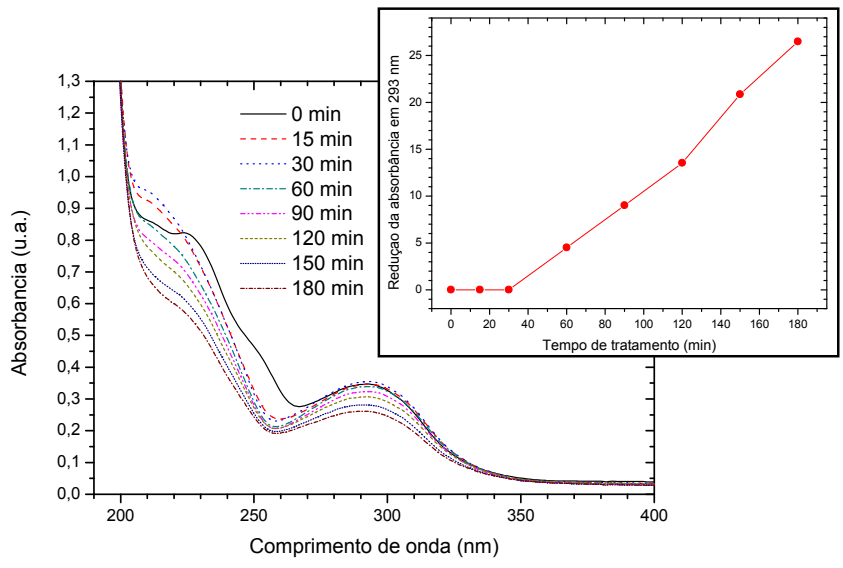

Conclusões

As análises por micrografia mostraram crescimento médio de $(268,4 \pm 20,4) \mathrm{nm}$ dos nanotubos de $\mathrm{TiO}_{2}$. A cristalização resultou na fase anatase, que é a mais fotoativa, pois foram observados intensos sinais em $2 \theta$ próximo a $25^{\circ}$. Foi possível obter $26 \%$ de redução do C.S. em $180 \mathrm{~min}$, evidenciando a atividade fotocatalítica dos nanotubos formados.

\section{Agradecimentos}

Ao CNPq, pela Bolsa de IC, ao Msc. Edvaldo L. Sousa, a graduanda Belisa Lima Soares e ao grupo do LADESSAM da Faculdade de Tecnologia.

CAVALEIRO, A.; HOSSON, J. TH. M. Nanostructured Coatings. Springer: New York, 2006, 671 p.

FRANÇA, M. D. Degradação de Paracetamol empregando Tecnologia Oxidativa Avançada baseada na Fotocatálise Heterogênea usando Irradiação Artificial e Solar. Dissertação de Mestrado. Universidade Federal de Uberlândia, 2011, 122 p.

MELO, S. A. et al.. Degradação de Fármacos Residuais por Processos Oxidativos Avançados. Quim. Nova, v.32, n.1, pp.188197, 2009. 